\title{
Correlation and prediction of arterial partial pressure of carbon dioxide from venous umbilical blood gases
}

\author{
Anucha Thatrimontrichai ${ }^{1 \oplus}$, Kan Charernjiratragul $^{1 \oplus}$, Waricha Janjindamai ${ }^{1 \oplus}$, \\ Supaporn Dissaneevate ${ }^{1 \oplus}$, Gunlawadee Maneenil ${ }^{1 \oplus}$, Manapat Phatigomet ${ }^{1 \oplus}$, \\ Nattachai Anantasit ${ }^{2}{ }^{2}$ \\ ${ }^{1}$ Department of Pediatrics, Faculty of Medicine, Prince of Songkla University, Songkhla, Thailand; ${ }^{2}$ Department of Pediatrics, Faculty of \\ Medicine, Ramathibodi Hospital, Mahidol University, Bangkok, Thailand.
}

\begin{abstract}
Background. Arterial partial pressure of carbon dioxide $\left(\mathrm{pCO}_{2}\right)$ samples are lower in children and higher in fetuses when compared with venous samples. The correlation and prediction of $\mathrm{pCO}_{2}$ from umbilical venous (UVBG) to umbilical arterial blood gas (UABG) dyad in neonates are identified.

Methods. A prospective study was performed from July 2018 to December 2019. Two dependent tests and a multivariate regression model were used to analyze the comparison and correlation tests.

Results. A total of 116 paired UABG and UVBG samples were obtained. The medians (interquartile ranges, IQR) were as follows: gestational age of 34 (29-37) weeks, birth weight of 2122 (1146-2839) g, and postnatal age of 2.3 (1.4-10.8) h. The median (IQR) $\mathrm{pCO}_{2(\mathrm{UABG})}$ and $\mathrm{pCO}_{2(\mathrm{UVBG})}$ measurements were 40.2 (33.5-45.8) and 40.4 $(34.7-46.8) \mathrm{mmHg}$, respectively (rho $=0.75, \mathrm{p}<0.001)$. The median of the differences (IQR) in $\mathrm{pCO}_{2(\mathrm{UABG})}$ and $\mathrm{pCO}_{2(\mathrm{UVBG})}$ was $-0.9(-4.7$ to 2.3$) \mathrm{mmHg},(\mathrm{p}=0.06)$. The equation to predict $\mathrm{pCO}_{2(\mathrm{UABG})}$ was $0.9 \times \mathrm{pCO}_{2(\mathrm{UVBG})}+4$, as derived from simple linear regression. The best model for predicting $\mathrm{pCO}_{2(\mathrm{UABG})}$ was $0.9 \times \mathrm{pCO}_{2(\mathrm{UVBG})}-0.7$ $\times$ venous base excess $+0.6 \times 5$-min Apgar score $+6.1 \times$ meconium aspiration syndrome $-7.7 \times$ patent ductus arteriosus - 6.5 (adjusted $\mathrm{r}^{2}=0.74$ ).
\end{abstract}

Conclusions. $\mathrm{pCO}_{2(\mathrm{UVBG})}$ correlates with and can predict $\mathrm{pCO}_{2(\mathrm{UABG})}$. Therefore, $\mathrm{pCO}_{2(\mathrm{UVBG})}$ can be applied to $\mathrm{pCO}_{2(\mathrm{UABG})}$ in neonates for whom UAC insertion is unsuccessful or to avoid an arterial puncture.

Key words: blood gas analysis, carbon dioxide, newborn, umbilical arteries, umbilical vein.

Partial pressure of carbon dioxide $\left(\mathrm{pCO}_{2}\right)$ from arterial blood gases $(\mathrm{ABG})$ is the gold standard in assessing ventilation. Hypercarbia and hypocarbia are associated with respiratory and neurologic complications. ${ }^{1}$ Moreover, the ventilator setting for respiratory acidosis or alkalosis needs to be adjusted. This usually should improve ventilatory treatment by optimizing tidal volumes, therefore reducing acute lung injury from volutrauma. ${ }^{2}$

\ Anucha Thatrimontrichai

tanucha@medicine.psu.ac.th

Received 25th February 2021, revised 5th May 2021, accepted 28th May 2021.
Umbilical arterial catheter (UAC), intermittent peripheral arterial punctures, or arterialized capillary blood samples can be used to directly measure ABG values in neonates. However, blood gases (BG) obtained by arterial or heel puncture are associated with the future development of cellulitis, abscess, necrotizing chondritis of the calcaneus cartilage, or calcaneal osteomyelitis and can cause severe pain in fragile neonates. A UAC can be used up to 5 days, whereas an umbilical venous catheter (UVC) can be used up to 14 days. ${ }^{3}$

To reduce the harmful effect of ventilatory support and promote gentle care in the neonatal intensive care unit (NICU), continuous noninvasive monitoring of ventilation $\left(\mathrm{CO}_{2}\right)$ is 
recommended. However, to date there have been few studies examining the agreement and correlation of both end-tidal carbon dioxide $\left(\mathrm{EtCO}_{2}\right)$ and transcutaneous carbon dioxide $\left(\mathrm{TcCO}_{2}\right)$ methods with arterial $\mathrm{pCO}_{2} \cdot{ }^{1}$

Compared with fetuses and children, neonates have a different anatomy and physiology. Between fetal and child circulation, neonatal circulation is intermediate. $\mathrm{pCO}_{2}$ levels from arterial samples in umbilical cord (fetal), ${ }^{4-8}$ neonates, ${ }^{9}$ and children/adults ${ }^{10-17}$ are physiologically higher, similar, and lower than venous samples, respectively. However, few studies have compared BGs in the neonatal period. The purpose of this study was to examine the correlation and prediction of $\mathrm{pCO}_{2}$ from UVBG to UABG ( $\mathrm{pCO}_{2(\mathrm{UVBG})}$ to $\left.\mathrm{pCO}_{2(\mathrm{UABG})}\right)$ dyads.

\section{Material and Methods}

\section{Settings and study design}

The STARD guidelines were followed in a prospective study conducted at a neonatal intensive care unit (NICU) in Thailand from July 1, 2018 to December 31, 2019. The study was approved by the Ethics Committee Board of the Faculty of Medicine, Prince of Songkla University (REC 60-383-01-1) and registered in the Thai Clinical Trials Registry (TCTR20180216001).

Neonates with both UAC and UVC readings available were the main inclusion criterion. The exclusion criteria were neonates with unstable vital signs, congenital heart disease, or the parents' decision not to participate. Umbilical blood was sampled by clinical indications. For BG analysis, after informed consent was provided, $0.2 \mathrm{~mL}$ each of UAB and UVB was drawn as simultaneously as possible (within $1 \mathrm{~min}$ ) from each catheter. No repeat samples were drawn from the same neonate (one paired sample per one neonate). An ABL800 BASIC (Radiometer Medical ApSTM, Denmark), a BG and electrolytes analyzer, was used to analyze all blood samples within 3 min after the blood was drawn.

\section{Statistical analysis}

To develop a categorical and continuous variable database, the $\mathrm{R}$ program (version 3.6.2, R Foundation for Statistical Computing, Vienna, Austria) was used. Categorical variables are presented as frequency and percentage. Parametric continuous variables are presented as mean (standard deviation, SD) and paired $t$-test was used to compare paired samples. Nonparametric continuous variables are presented as median (interquartile range, IQR) and the Wilcoxon signed rank test with continuity correction was used to compare paired samples. Pearson (parametric variables; $r$ ) and Spearman's rank (nonparametric variables; Q) tests were used to analyze correlations. The cutoff points of postnatal age (for comparison) and $\mathrm{pCO}_{2}$ level (for correlation) for the subgroup analysis were $24 \mathrm{~h}$ and $35-45 \mathrm{mmHg}$ (normocarbia), respectively. Patent ductus arteriosus (PDA) is functionally closed by $24 \mathrm{~h}$ after birth.

For $\mathrm{pCO}_{2(\mathrm{UABG})}$ prediction, simple and multivariate linear regression were used. Significant variables from previous studies for $\mathrm{pCO}_{2(\mathrm{UVBG})}$, venous base excess (VBE), gestational age, ${ }^{4,18}$ postnatal age, 5-min Apgar score, ${ }^{9}$ and respiratory problems (binary variables including respiratory distress syndrome (RDS), meconium aspiration syndrome (MAS), pneumonia, and PDA $)^{19}$ were entered to adjust the outcome. The most parsimonious model was determined by the multivariate analysis model with the lowest Akaike information criteria (AIC). Sample size was calculated as a minimum of 30 neonates based on a previous study, but we increased the number of participants to 116 neonates to increase the power of the study. G*Power version 3.1.9.2 was used to calculate post hoc power analysis. All p-values were two-tailed, and values less than 0.05 indicated statistical significance. 


\section{Results}

One hundred sixteen paired UABG and UVBG samples were tested in the study. The medians (IQRs) of gestational age, birth weight, and time of performing the blood gas analyses were 34 (29-37) weeks, 2122 (1146-2839) g, and 2.3 (1.410.8) h, respectively. BG measurements of 96 neonates $(83 \%)$ were obtained within $24 \mathrm{~h}$ of birth. Apgar 1-min and 5-min median (IQR) scores were 7 (4-8) and 8 (6-9), respectively. The enrolled neonates had incidences of RDS of $50 \%$, MAS of $8 \%$, pneumonia of $7 \%$, and PDA $7 \%$. During blood gas collection, the numbers (percentage) of neonates on respiratory or oxygen support with high-frequency oscillation, assist-control, synchronized intermittent mandatory ventilation, bilevel positive airway pressure, and high flow nasal cannula were $64(55.2 \%), 44(37.9 \%), 6(5.2 \%), 1(0.9 \%)$, and 1 $(0.9 \%)$, respectively.

Figure 1 shows the scatterplot between $\mathrm{pCO}_{2(\mathrm{UABG})}$ and $\mathrm{pCO}_{2(\mathrm{UVBG})} \cdot \mathrm{pCO}_{2(\mathrm{UABG})}$ had a median (IQR) of $40.2(33.5-45.8) \mathrm{mmHg}$ and $\mathrm{pCO}_{2(\mathrm{UVBG})}$ had 40.4 (34.7-46.8) $\mathrm{mmHg}$ ( $\mathrm{Q}=0.75$, $\mathrm{p}<0.001)$. The median of the differences (IQR) between $\mathrm{pCO}_{2(\mathrm{UABG})}$ and $\mathrm{pCO}_{2(\mathrm{UVBG})}$ was -0.9
$(-4.7$ to 2.3$) \mathrm{mmHg}$ ( $\mathrm{p}=0.06$; post hoc power $=$ $100)$. The box plots of the differences between $\mathrm{pCO}_{2(\mathrm{UABG})}$ and $\mathrm{pCO}_{2(\mathrm{UVBG})}$ for each gestational age are shown in Figure 2. In addition, the mean $\pm \mathrm{SD}$ of $\mathrm{pCO}_{2(\mathrm{UABG})}$ was $40.9 \pm 13.6$ and $\mathrm{pCO}_{2(\mathrm{UVBG})}$ was $41.6 \pm 12.6 \mathrm{mmHg}(r=0.82)$. The mean of the differences (95\% confidence interval) between $\mathrm{pCO}_{2(\mathrm{UABG})}$ and $\mathrm{pCO}_{2(\mathrm{UVBG})}$ was -0.7 (-2.2 to 0.7) $\mathrm{mmHg}(\mathrm{p}=0.33)$. All other parameters of the blood gases are shown in Table I.

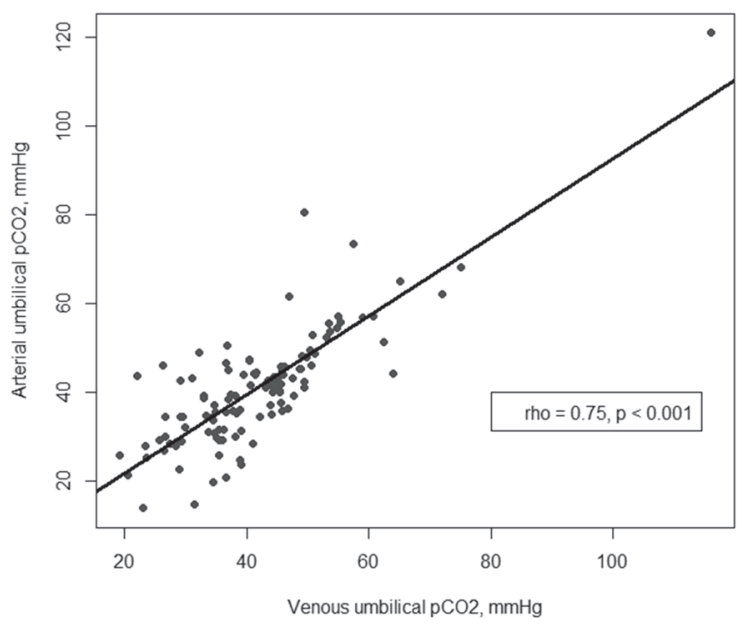

Fig. 1. The scatterplot between arterial and venous umbilical $\mathrm{pCO}_{2}$.

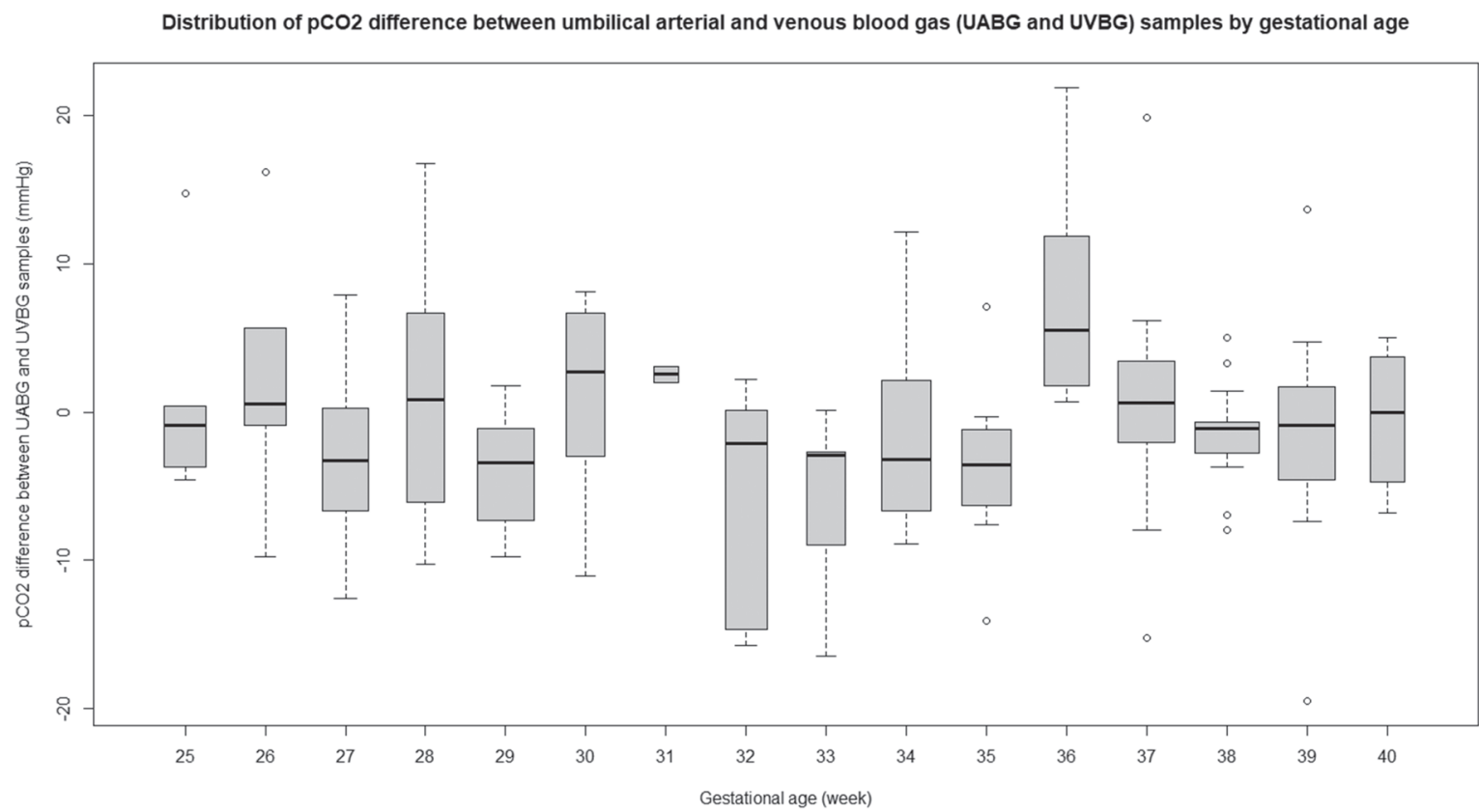

Fig. 2. The box plots of the differences between $\mathrm{pCO}_{2(\mathrm{UABG})}$ and $\mathrm{pCO}_{2(\mathrm{UVBG})}$ for each gestational age. 
Table I. Comparison between umbilical arterial and venous blood gas (UABG and UVBG) of $\mathrm{pH}, \mathrm{pCO}_{2^{\prime}} \mathrm{pO}_{2^{\prime}}$ $\mathrm{HCO}_{3^{\prime}}$ and base excess values.

\begin{tabular}{lcccc}
\hline & \multicolumn{1}{c}{$\mathrm{UABG}^{*}$} & $\mathrm{UVBG}^{*}$ & $\mathrm{UABG}-\mathrm{UVBG}$ & $\mathrm{p}$-value \\
\hline $\mathrm{pH}$ & $7.30(7.26,7.36)$ & $7.30(7.24,7.35)$ & $0.01(-0.01,0.02)$ & 0.05 \\
$\mathrm{pCO}_{2^{\prime}} \mathrm{mmHg}$ & $40.2(33.5,45.8)$ & $40.4(34.7,46.8)$ & $-0.9(-4.7,2.3)$ & 0.06 \\
$\mathrm{pO}_{2^{\prime}} \mathrm{mmHg}$ & $71.3(58.7,101.0)$ & $51.0(40.5,61.7)$ & $19.9(9.5,43.0)$ & $<0.001$ \\
$\mathrm{HCO}_{3^{\prime}} \mathrm{mEq} / \mathrm{L}$ & $19.1(17.4,20.7)$ & $19.2(16.7,20.4)$ & $-0.1(-0.8,1.0)$ & 0.78 \\
Base excess & $-6.60(-8.75,-4.38)$ & $-6.45(-10.00,-4.70)$ & $-0.30(-1.10,1.30)$ & 0.69 \\
\hline
\end{tabular}

*median (interquartile range)

The median of the differences (IQR) for the subgroup analysis between $\mathrm{pCO}_{2(\mathrm{UABG})}$ and $\mathrm{pCO}_{2(\mathrm{UVBG})}$ within $24 \mathrm{~h}$ of birth was $-0.8(-4.5$ to 2.6) $\mathrm{mmHg}(\mathrm{Q}=0.73, \mathrm{p}=0.19)$. The mean of the differences \pm SD between $\mathrm{pCO}_{2(\mathrm{UABG})}$ and $\mathrm{pCO}_{2(\mathrm{UVBG})}$ after $24 \mathrm{~h}$ of life was $-2.5 \pm-5.6$ $\mathrm{mmHg},(r=0.89 ; \mathrm{p}=0.06)$. As shown in Table II, a $\mathrm{pCO}_{2}$ level of 35-45 mmHg had $87 \%$ sensitivity, $94 \%$ specificity, 15.05 positive likelihood ratio, 0.14 negative likelihood ratio, and 91\% accuracy of correlation.

The equation $\mathrm{pCO}_{2(\mathrm{UABG})}=0.9 \times \mathrm{pCO}_{2(\mathrm{UVBG})}+4$, from the simple linear regression, was used to predict $\mathrm{pCO}_{2(\mathrm{UABG})}\left(r^{2}=0.68\right)$. The final factors to predict $\mathrm{pCO}_{2(\mathrm{UABG})}$ in the parsimonious model $(\mathrm{AIC}=786.6)$ were $\mathrm{pCO}_{2(\mathrm{UVBG})}, \mathrm{VBE}, 5$-min Apgar score, MAS, and PDA; all of these variables were statistically significantly different in the multivariate linear regression analysis, as shown in Table III. The equation $\mathrm{pCO}_{2(\mathrm{UABG})}=$ $0.9 \times \mathrm{pCO}_{2(\mathrm{UVBG})}-0.7 \times \mathrm{VBE}+0.6 \times 5$-min Apgar score + 6.1 $\times$ MAS - $7.7 \times$ PDA - 6.5 (adjusted $r^{2}=$ 0.74 ) was the best model for predicting arterial $\mathrm{pCO}_{2}$ values.

\section{Discussion}

The study has some clinical implications. Previous studies indicated that the $\mathrm{pCO}_{2}$ mean differences ranges between venous and arterial samples were 3.9-4.4 in adults, ${ }^{10,11}$ 3.57.3 in children, ${ }^{12-16} 0.9$ in neonates (one study published more than $50 \mathrm{y}$ ago), ${ }^{9}$ and -10 to

Table II. Correlation between arterial and venous $\mathrm{pCO}_{2}$ values.

\begin{tabular}{ccccc}
\hline & & \multicolumn{3}{c}{$\mathrm{pCO}_{2(\mathrm{UABG})^{\prime}} \mathrm{mmHg}$} \\
\cline { 3 - 5 } & & $<35$ & $35-45$ & $>45$ \\
\cline { 2 - 5 } $\mathrm{pCO}_{2(\mathrm{UVBG})^{\prime}} \mathrm{mmHg}$ & $355-45$ & 32 & 0 & 0 \\
& $>45$ & 4 & 41 & 0 \\
\hline
\end{tabular}

$\mathrm{pCO}_{2(\mathrm{UABG})}$ : partial pressure of carbon dioxide from umbilical arterial blood gas, $\mathrm{pCO}_{2(\mathrm{UVBG})}$ : partial pressure of carbon dioxide from umbilical venous blood gas

Table III. Multivariate linear regression for prediction of $\mathrm{pCO}_{2}$ in umbilical arterial blood gas.

\begin{tabular}{lcccc}
\hline Variable & Coefficient & Standard error & t-value & p-value \\
\hline Intercept & -6.5 & 3.84 & -1.70 & 0.09 \\
$\mathrm{pCO}_{2(\mathrm{UVBG})}$ & 0.9 & 0.05 & 17.48 & $<0.001$ \\
Venous base excess & -0.7 & 0.14 & -4.76 & $<0.001$ \\
5-min Apgar score & 0.6 & 0.29 & 2.01 & 0.046 \\
Meconium aspiration syndrome & 6.1 & 2.43 & 2.51 & 0.01 \\
Patent ductus arteriosus & -7.7 & 2.58 & -2.98 & 0.003 \\
\hline
\end{tabular}

$\mathrm{pCO}_{2(\mathrm{UVBG})}$ : partial pressure of carbon dioxide from umbilical venous blood gas 
$-14 \mathrm{mmHg}$ from umbilical cord (fetal) ${ }^{4-8}$ blood samples. Most studies were based on umbilical cord (fetal) sampling. To increase the statistical power, this study in neonates used a larger sample size (116 neonates) than the previous study (18 neonates). ${ }^{9}$ In this study, the difference in $\mathrm{pCO}_{2}$ between venous and arterial blood gas $(0.7 \mathrm{mmHg}$ ) was consistent with the previous study $(0.9 \mathrm{mmHg}){ }^{9}$

In our study, $17 \%$ of the blood samples were drawn after 24 hours of birth, whereas none of the blood samples were acquired within this time in the previous study. ${ }^{9} \mathrm{pCO}_{2(\mathrm{UABG})}$ and $\mathrm{pCO}_{2(\mathrm{UVBG})}$ showed a strong correlation and no differences in blood measurements obtained more than $24 \mathrm{~h}$ after birth. Based on our findings, a cutoff point of $\mathrm{pCO}_{2}$ was established, at which a high correlation for $\mathrm{pCO}_{2}(35-45 \mathrm{mmHg}$ ) levels was observed between the arterial and venous samples, and moderate to strong correlation in postnatal ages within and after $24 \mathrm{~h}$ after birth.

There were neither significant clinical (0.9 $\mathrm{mmHg})$ nor statistical $(\mathrm{p}=0.06$; post hoc power $=100 \%$ ) differences between paired $\mathrm{pCO}_{2(\mathrm{UABG})}$ and $\mathrm{pCO}_{2(\mathrm{UVBG})}$. The equations $\mathrm{pCO}_{2(\mathrm{UABG})}=0.9$ $\times \mathrm{pCO}_{2(\mathrm{UVBG})}+4$ (simple) and $\mathrm{pCO}_{2(\mathrm{UABG})}=0.9 \times$ $\mathrm{pCO}_{2(\mathrm{UVBG})}-0.7 \times \mathrm{VBE}+0.6 \times 5$-min Apgar score $+6.1 \times$ MAS - $7.7 \times$ PDA - 6.5 (regression) were used to predict $\mathrm{pCO}_{2(\mathrm{UABG})}$. A UVC can be used longer than a UAC insertion. Therefore, in neonates in whom UAC insertion is unsuccessful or to avoid an arterial puncture, $\mathrm{pCO}_{2(\mathrm{UVBG})}$ can be applied to $\mathrm{pCO}_{2(\mathrm{UABG})}$.

The trend and real-time assessment of arterial $\mathrm{pCO}_{2}$ can be monitored continuously and noninvasively. In prospective studies between EtCO $\mathrm{C}_{2}$ and $\mathrm{pCO}_{2}$, the average mean difference was 7 (range 2-11) and the correlation coefficient was 0.7. ${ }^{1}$ Between $\mathrm{TcCO}_{2}$ and $\mathrm{pCO}_{2^{\prime}}$ the average mean difference was 2 and the correlation coefficient was $0.9 .{ }^{1}$ In this study, the mean difference and correlation coefficient were less than 1 and 0.82, respectively. Moreover, clinical implications for both methods has limitations. The $\mathrm{EtCO}_{2}$ analysis can be influenced by ventilation-perfusion mismatches, or kinks or secretion obstructions in the endotracheal tube, and cannot be used currently during noninvasive or high-frequency ventilation (not accurate due to small tidal volume and higher respiratory rate). ${ }^{1}$ The $\mathrm{TcCO}_{2}$ analysis influences heat-induced skin damage from the electrodes, which affects reliability due to technical limitations (skin edema, poor tissue perfusion, acidosis sensor preparation, positioning, and repeated changes of location), initial measurement takes time and response time is slower when compared with $\mathrm{EtCO}_{2}{ }^{1}$

This study had some limitations. First, some confounders of $\mathrm{pCO}_{2}$ levels in previous studies are as follows: VBE, gestational age, postnatal age, Apgar score, and respiratory problems (RDS, MAS, pneumonia, and PDA) from the previous studies; however, analysis was adjusted by multivariate regression. Second, UVBG and UABG in a previous ${ }^{9}$ and this study were compared from post-ductal samples. Most ductus arteriosus close within $24 \mathrm{~h}$ after birth, which affects circulation. Echocardiography was performed only on patients with suspected PDA. Information bias may have occurred because during the study period, echocardiography was not normally performed while obtaining BG. Finally, we are curious when the arteriovenous $\mathrm{pCO}_{2}$ difference in neonates $(-0.9 \mathrm{mmHg})$ becomes similar to children and adults (4-6 mmHg).

This study found a strong correlation and no significant difference between $\mathrm{pCO}_{2(\mathrm{UABG})}$ and $\mathrm{pCO}_{2(\mathrm{UVBG})}$ as well as within and after 24 $h$ after birth. Thus, we suggest that $\mathrm{pCO}_{2(\mathrm{UVBG})}$ values can be substituted for $\mathrm{pCO}_{2(\mathrm{UABG})}$. Further studies are needed to determine the time after birth neonatal differences in $\mathrm{pCO}_{2}$ between $\mathrm{ABG}$ and VBG become equal to children and adults.

\section{Ethical approval}

The study was approved by the Ethical Committee Board of Faculty of Medicine, Prince of Songkla University (REC 60-383-01-1). 


\section{Author contribution}

AT, WJ, SD, GM and MP designed the study. AT and KC collected and analyzed the data. AT, KC, WJ, SD, GM and MP drafted the manuscript. AT and NA analyzed, interpreted of data, and critically revised the manuscript for important intellectual content. All authors have read, and approved the final manuscript. AT will act as Guarantor for this paper.

\section{Source of funding}

This study was funded by Faculty of Medicine, Prince of Songkla University.

\section{Conflict of interest}

The authors declare that there is no conflict of interest.

\section{REFERENCES}

1. Hochwald O, Borenstein-Levin L, Dinur G, Jubran H, Ben-David S, Kugelman A. Continuous noninvasive carbon dioxide monitoring in neonates: from theory to standard of care. Pediatrics 2019; 144: e20183640. https://doi.org/10.1542/peds.2018-3640

2. Thatrimontrichai A, Janjindamai W. Volume targeted ventilator of newborn. J Health Sci Med Res 2010; 28: 155-167.

3. Polin RA, Denson S, Brady MT, Committee on Fetus and Newborn; Committee on Infectious Diseases. Strategies for prevention of health care-associated infections in the NICU. Pediatrics 2012; 129: e1085-e1093. https://doi.org/10.1542/peds.2012-0145

4. Dickinson JE, Eriksen NL, Meyer BA, Parisi VM. The effect of preterm birth on umbilical cord blood gases. Obstet Gynecol 1992; 79: 575-578.

5. Kotaska K, Urinovska R, Klapkova E, Prusa R, Rob $\mathrm{L}$, Binder T. Re-evaluation of cord blood arterial and venous reference ranges for $\mathrm{pH}, \mathrm{pO}(2), \mathrm{pCO}(2)$, according to spontaneous or cesarean delivery. J Clin Lab Anal 2010; 24: 300-304. https://doi.org/10.1002/ jcla.20405

6. Yeomans ER, Hauth JC, Gilstrap LC 3rd, Strickland DM. Umbilical cord $\mathrm{pH}, \mathrm{PCO}$, and bicarbonate following uncomplicated term vaginal deliveries. Am J Obstet Gynecol 1985; 151: 798-800. https://doi. org/10.1016/0002-9378(85)90523-X
7. Helwig JT, Parer JT, Kilpatrick SJ, Laros RK Jr. Umbilical cord blood acid-base state: what is normal? Am J Obstet Gynecol 1996; 174: 1807-1812. https://doi.org/10.1016/S0002-9378(96)70214-4

8. Valenzuela P, Guijarro R. The effects of time on $\mathrm{pH}$ and gas values in the blood contained in the umbilical cord. Acta Obstet Gynecol Scand 2006; 85: 1307-1309. https://doi.org/10.1080/00016340600697488

9. MacRae DJ, Palavradji D. Comparison between arterial, capillary and venous acid-base measurements in the newborn infant. J Obstet Gynaecol Br Commonw 1966; 73: 761-765. https:// doi.org/10.1111/j.1471-0528.1966.tb06080.x

10. Byrne AL, Bennett M, Chatterji R, Symons R, Pace NL, Thomas PS. Peripheral venous and arterial blood gas analysis in adults: are they comparable? A systematic review and meta-analysis. Respirology 2014; 19: 168-175. https://doi.org/10.1111/resp.12225

11. Bloom BM, Grundlingh J, Bestwick JP, Harris T. The role of venous blood gas in the emergency department: a systematic review and meta-analysis. Eur J Emerg Med 2014; 21: 81-88. https://doi. org/10.1097/MEJ.0b013e32836437cf

12. Furqan M, Hashmat F, Amanullah M, Khan M, Durani HK, Anwar ul H. Venoarterial PCO2 difference: a marker of postoperative cardiac output in children with congenital heart disease. J Coll Physicians Surg Pak 2009; 19: 640-643.

13. Rhodes LA, Erwin WC, Borasino S, Cleveland DC, Alten JA. Central venous to arterial CO2 difference after cardiac surgery in infants and neonates. Pediatr Crit Care Med 2017; 18: 228-233. https://doi. org/10.1097/PCC.0000000000001085

14. Yildizdaș D, Yapicioğlu H, Yilmaz HL, Sertdemir Y. Correlation of simultaneously obtained capillary, venous, and arterial blood gases of patients in a paediatric intensive care unit. Arch Dis Child 2004; 89: 176-180. https://doi.org/10.1136/adc.2002.016261

15. Adrogue $\mathrm{HJ}$, Rashad $\mathrm{MN}$, Gorin $\mathrm{AB}$, Yacoub J, Madias NE. Assessing acid-base status in circulatory failure. Differences between arterial and central venous blood. N Engl J Med 1989; 320: 1312-1316. https://doi.org/10.1056/NEJM198905183202004

16. Singh NG, Prasad SR, Manjunath V, et al. Evaluation of adjusted central venous blood gases versus arterial blood gases of patients in post-operative paediatric cardiac surgical intensive care unit. Indian J Anaesth 2015; 59: 630-635. https://doi.org/10.4103/00195049.167492

17. Kirubakaran C, Gnananayagam JE, Sundaravalli EK. Comparison of blood gas values in arterial and venous blood. Indian J Pediatr 2003; 70: 781-785. https://doi.org/10.1007/BF02723794 
18. Matsuo K, Malinow AM, Harman CR, Baschat AA. Umbilical arterial-venous blood gas difference: a novel expression of placental respiratory function. Am J Perinatol 2009; 26: 199-206. https://doi. org/10.1055/s-0028-1103029
19. McDonald MJ, Montgomery VL, Cerrito PB, Parrish CJ, Boland KA, Sullivan JE. Comparison of end-tidal $\mathrm{CO} 2$ and $\mathrm{Paco} 2$ in children receiving mechanical ventilation. Pediatr Crit Care Med 2002; 3: 244-249. https://doi.org/10.1097/00130478-200207000-00008 